\section{Hacia un enfoque práctico para determinar pacientes vulnerables en el proceso de toma del consentimiento informado}

\section{Mussi, Rodolfo}

Miembro de Comité de Ética en Investigación Clínica del CECIC, InAER, Gedyt y TCba. E-mail rodolfomussi@yahoo.com.ar

PALAVRAS-CHAVE: ética de la investigación en salud, vulnerabilidad, consentimiento informado, paciente vulnerable, comités de ética.

En el campo de la ética de la investigación de salud existe bibliografía en relación a las características presentes en poblaciones vulnerables y guías y pautas orientativas que establecen las conductas éticas que los patrocinantes y los investigadores de ensayos clínicos deben seguir. También, la bibliografía y las guías proporcionan diferentes definiciones de poblaciones vulnerables pero no es menos cierto que también hay críticas a las mismas por ser consideradas poco precisas. Un aspecto muy importante en la labor de los investigadores principales es la atención de pacientes vulnerables y al respecto, en muchos casos, no encuentran un marco delimitado que les permita poder determinar si el paciente en cuestión es vulnerable o no. Queda claro que a partir de las distintas definiciones, en términos generales, se considera vulnerable a aquel paciente que no puede protegerse así mismo (de éste núcleo conceptual primordial, se derivan distintos análisis). Sin embargo, en la práctica cotidiana de los comités de ética en investigación clínica, a menudo se presentan casos o requerimientos por partes de los investigadores sobre cómo actuar y poder razonablemente establecer si un paciente es vulnerable o no. En el presente artículo esbozaremos una guía orientativa que le permita al IP establecer cuando un paciente es vulnerable o no, lo cual nos conduce previamente redefinir el concepto de vulnerabilidad entendido como situacional, y a partir de un enfoque casuístico, discernir sobre la vulnerabilidad o no del paciente voluntario que manifiesta su voluntad de participar en un ensayo clínico. En conclusión, esbozaremos una orientación práctica a ser aplicada en el proceso de toma de consentimiento informado que debiera contener características propias según la región en dónde el ensayo clínico sea realizado.

AGRADECIMENTOS: A todos los colegas miembros de comités de ética propios y de otros que con el compartir del trabajo diario y sus comentarios sobre el presente ayudan a mi perfeccionamiento profesional constante.

\section{REFERÊNCIAS:}

[1] F. Luna, Diálogo sobre vulnerabilidad; Elucidating the concept of vulnerability: layers not labels; The
International Journal of Feminist Approaches to Bioethics, vol. $2 \mathrm{n}^{\circ}$, Spring 2009.

[2] R. Prosperi, Criterios para establecer prioridades en la investigación universitaria en salud: la perspectiva de los investigadores; Revista Redbioética/UNESCO, año 4, 1 (7), enero-junio 2013.

[3] J. E. de Siqueira; Análisis crítico del artículo del Prof. Jan Helge Solbakk en el prisma del Principio de Responsabilidad de Hans Jonas; Revista Redbioética/UNESCO, año 2, (4), julio-diciembre 2011.

[4] M. Kottow, Anotaciones sobre vulnerabilidad; Revista Redbioética/UNESCO, año 2, 2 (4), enero-junio 2011.

[5] L. Justo, Participatory Research: A way to reduce vulnerability; The American Journal of Bioethics, 4: 3, 67, First published on: 17 August 2010. 